4 Levine DF, Bleakley A. Maximising medicine through aphorisms. Med Educ 2011 (in press).

5 Levine DF. Personal observations.

\section{In response}

In response to the thoughtful comments of Levine and Bleakley we are pleased to reemphasise the principal purpose of our paper.

Cognitive shortcuts were first identified as key triggers of errors in judgement and decision taking. ${ }^{1}$ Subsequently this view was challenged by researchers who have shown the value of 'cognitively hard-wired' systems in making sense of complex situations. ${ }^{2}$ Clearly, 'intuition' plays a part in the diagnostic process. However, in our analyses of case records of emergency admissions, we were perturbed to find that the conclusions of clinical clerking by trainees usually appear under the term 'Imp' (ie impression). This term is nonspecific and as a result follow-up actions may be ill-defined.

Recent evidence demonstrates that 'getting it right' using intuition is a marker of expertise. Experienced doctors may be able to arrive at the correct answer very quickly - their expertise has become cognitively implicit. Psychologists have developed a number of techniques to examine this aspect of expertise (including cognitive task analysis and verbal protocol analysis). ${ }^{3}$ We conclude that intuition-based decision making may work well for an expert diagnostician but is likely to be less fruitful for a trainee physician.

In the light of this evidence we suggest that junior members of the care team should use a systems approach to back up initial thoughts. In caring for older patients, clinicians often face a complex web of possibilities. The proposed simple tabulated format (charting observations, conclusions and resultant actions) allows the team to create a plan for a patient, to share it adequately (including during handovers), and to provide follow-up.

We agree that diagnosis is a non-linear, dynamic cognitive process. It is exactly for this reason that a tabulated plan could help render the process more tractable. Care plans have been shown to improve outcomes in intensive care units. ${ }^{4}$ However, it is likely that such changes in process can only come from central directives. If it could be shown, in a prospective study, that tabulated observations, conclusions and resultant actions (of the type proposed) significantly enhance the process of assessing acute admissions to hospital, then it would seem reasonable to add such tabulations to the 'generic medical recordkeeping standards' proposed by the Royal College of Physicians in 2007 and accepted by more than $80 \%$ of physicians. ${ }^{5}$

$$
\begin{array}{r}
\text { GRAHAM NEALE } \\
\text { Visiting professor, } \\
\text { Centre for Patient Safety and Quality, } \\
\text { Department of Surgery and Cancer, } \\
\text { Imperial College, London } \\
\text { HELEN HOGAN } \\
\text { Lecturer in public health and } \\
\text { MScPH course director, } \\
\text { London School of Hygiene and Public Health } \\
\text { NICK SEVDALIS } \\
\text { Senior lecturer, } \\
\text { Centre for Patient Safety and Quality, } \\
\text { Department of Surgery and Cancer, } \\
\text { Imperial College, London }
\end{array}
$$

\section{References}

1 Tversky A, Kahneman D. Judgment under uncertainty: heuristics and biases. Science 1974;185:1124-31.

2 Gigerenzer G, Todd PM. ABC Research Group. Simple heuristics that make us smart. New York: Oxford University Press, 1999.

3 Klein G. Sources of power - how people make decisions. Cambridge, MA: MIT Press, 1999.

4 Pronovost P, Berenholtz S, Dorman T et al. Improving communication in the ICU using daily goals. J Crit Care 2003;18: 71-5.

5 Carpenter I, Bridgelal Ram M, Croft GP, Williams JG. Medical records and recordkeeping standards. Clin Med 2007;7:328-31.

\section{Including pharmacists on consultant-led ward rounds}

Editor - Miller and colleagues highlight the useful interventions of pharmacists in prescribing on consultant-led ward rounds (Clin Med August 2011 pp 312-16). We have previously shown how giving feed- back to junior doctors on consultant-led ward rounds can lead to a reduction in prescribing errors. ${ }^{1}$ However, a major problem with this approach is that the doctor who wrote the drug chart is often not present on the round, as patients are quickly moved from the on-call or acute medical team to another ward. We therefore extended our work to a one-year study in which the pharmacist gave feedback to foundation year (FY) 1 doctors responsible for moderate or severe prescribing errors irrespective of the ward they worked on. Drug charts and take home prescriptions were systematically reviewed on three medical and one surgical ward by a single designated ward pharmacist who conducted the study. Feedback was given by the pharmacist face-to-face whenever possible $58 \%$ or errors), by telephone $(26 \%)$ or by email if the trainee was otherwise difficult to contact $(16 \%)$. The feedback was supplemented by six formal teaching sessions in which the prescribing errors were discussed in anonymised fashion.

In total, 275 errors were recorded by 25 FY1 doctors. The two most common errors were due to incorrect medication history itself, followed by wrong dose. There was a $62.8 \%$ reduction in total prescribing errors over the course of the year from 86 in the first eight weeks to 32 in the final eight weeks. Severe errors reduced by $92.3 \%$ from 13 in the first eight weeks to one in the final eight weeks. A questionnaire evaluation of the FY1 doctors' perceptions of the study revealed an overall feeling that providing feedback in this way was useful and effective. Six FY1s revealed that they had never received prescribing feedback from a senior member of their medical team.

An important goal of ward pharmacists should be to educate. Receiving feedback on performance is the most powerful way to learn. ${ }^{2}$ Our study shows that pharmacists giving feedback to trainees on prescribing errors is feasible and effective even though they may not be working on the ward in which the errors were detected.

SIMON QUANTRILL

Consultant physician

DANIELLA WEBBE

Pharmacist

Whipps Cross University Hospital, London 


\section{References}

1 Webbe D, Dhillon S, Roberts CM. Improving junior doctor prescribing - the positive impact of a pharmacist intervention. Pharm J 2007;278:136-9.

2 Ende J. Feedback in clinical medical education. JAMA 1983;250:777-81.

\section{In response}

We thank Quantrill and Webbe for their response, and agree completely both that an important role of pharmacists is to educate, and that better systems are needed for providing feedback to prescribers about any errors made. We believe that feedback is complementary to pharmacist attendance on consultant ward rounds, and that both approaches are required. Pharmacists attending ward rounds are likely to be more aware of patients' current priority medical problems, and are able to discuss drug therapy with senior members of the medical team, resulting in the higher intervention rate demonstrated in our paper. Separately, better feedback on prescribing errors, particularly to junior doctors, is also needed, to facilitate learning. Several studies have shown that junior doctors get little or no feedback on their prescribing errors at present. We recently completed some exploratory work with junior doctors and pharmacists to explore these issues, and found a key barrier to be pharmacists unable to ascertain the identity of the prescriber. We are therefore considering piloting the use of name stamps, and are designing a controlled study to explore the impact of providing feedback to our junior doctors. We would encourage Quantrill and Webbe to publish their findings in more detail so that others can build on them further.

GAVIN MILLER Lead pharmacist, clinical services, Pharmacy Department

BRYONY DEAN FRANKLIN Director, Centre for Medication Safety and Service Quality

ANN JACKLIN

Chief of service pharmacy and therapies,

Imperial College Healthcare NHS Trust, London

\section{'The tubercular diabetic'}

Editor - We read with great interest the article by Bailey and colleagues (Clin Med August 2011 pp 344-7). Treatment of people with tuberculosis (TB) and diabetes is indeed complicated. Not only does rifampicin potentially adversely alter the pharmacokinetics of gliclazide, ${ }^{1}$ glipizide, ${ }^{2}$ pioglitazone, ${ }^{3}$ nateglinide ${ }^{4}$ and repaglinide,${ }^{5}$ but like isoniazid, it may increase insulin requirements. ${ }^{6}$ Liver and nerve toxicity from anti-TB drugs may be difficult to distinguish from diabetes-associated non-alcoholic fatty liver disease and peripheral neuropathy respectively and for those with co-morbid HIV infection with access to treatment, there is the added complication of antiretroviral-associated insulin resistance. ${ }^{7}$ TB itself may precipitate hyperglycaemia by a stress hormone response and there is some evidence of glucose intolerance in TB patients reverting to normal in up to $75 \%$ of patients after three months of TB treatment. ${ }^{8}$

We wholeheartedly endorse Bailey and Grant's conclusion that TB and diabetes demand increased attention from clinicians and academics if we are to ensure that future patients receive optimal management of both conditions.

HEMANTHA CHANDRASEKARA

Specialty registrar in endocrinology and diabetes, Royal Liverpool University Hospital

KEVIN HARDY

Consultant in endocrinology and diabetes,

Whiston Hospital,

Prescot, Merseyside

\section{References}

1 Park JY, Kim KA, Park PW, Park CW, Shin JG. Effect of rifampin on the pharmacokinetics and pharmacodynamics of gliclazide. Clin Pharmacol Ther 2003;74:334-40.

2 Niemi M, Backman JT, Neuvonen M, Neuvonen PJ, Kivisto KT. Effects of rifampin on the pharmacokinetics and pharmacodynamics of glyburide and glipizide. Clin Pharmacol Ther 2001;69:400-6.

3 Jaakkola T, Backman JT, Neuvonen M, Laitila J, Neuvonen PJ. Effect of rifampicin on the pharmacokinetics of pioglitazone. Br J Clin Pharmacol 2006;61:70-8.

4 Niemi M, Backman JT, Neuvonen M, Neuvonen PJ. Effect of rifampicin on the pharmacokinetics and pharmacodynamics of nateglinide in healthy subjects. $\mathrm{Br} \mathrm{J} \mathrm{Clin}$ Pharmacol 2003;56:427-32.

5 Hatorp V, Hansen KT, Thomsen MS. Influence of drugs interacting with CYP3A4 on the pharmacokinetics, pharmacodynamics, and safety of the prandial glucose regulator repaglinide. J Clin Pharmacol 2003;43:649-60.

6 Atkin SL, Masson EA, Bodmer CW, Walker BA, White MC. Increased insulin requirement in a patient with type 1 diabetes on rifampicin. Diabet Med 1993;10:392.

7 Tebas P. Insulin resistance and diabetes mellitus associated with antiretroviral use in HIV-infected patients: pathogenesis, prevention, and treatment options.

J Acquir Immune Defic Syndr 2008;49

(Suppl 2):S86-92.

8 Oluboyo PO, Erasmus RT. The significance of glucose intolerance in pulmonary tuberculosis. Tubercle 1990;71:135-8.

\section{In response}

We read with appreciation the comments of Chandrasekara and Hardy. The management of concomitant tuberculosis and diabetes mellitus remains challenging and highlights two important factors. Firstly, that our level of clinical suspicion of dual pathology here in the UK needs to be raised so that management can be optimised, including appropriate adjustment and monitoring of medication. Secondly, that as diabetes progresses in low-income countries we need to consider collectively how best to manage this chronic disease in resource-limited settings and indeed this is a focus of our ongoing research.

PAUL GRANT

Specialist registrar in diabetes and endocrinology,

King's College Hospital, London

SARAH LOU BAILEY

Clinical lecturer in infectious diseases and global health,

Brighton and Sussex Medical School

\section{Oxygen therapy in acute coronary syndrome: current NICE recommendations}

Editor - I read with great interest the concise guidance by O'Driscoll and colleague (Clin Med August 2011, pp 372-5) on emergency oxygen use in adult patients. Oxygen therapy 